\title{
BMJ Open Potential for advice from doctors to reduce the number of patients referred to emergency departments by NHS 111 call handlers: observational study
}

\author{
Andrew Anderson, ${ }^{1}$ Martin Roland ${ }^{2}$
}

To cite: Anderson A, Roland M. Potential for advice from doctors to reduce the number of patients referred to emergency departments by NHS 111 call handlers: observational study. BMJ Open 2015;5:e009444. doi:10.1136/bmjopen-2015009444

- Prepublication history for this paper is available online. To view these files please visit the journal online (http://dx.doi.org/10.1136/ bmjopen-2015-009444).

Received 11 August 2015 Revised 19 October 2015 Accepted 4 November 2015

CrossMark

\footnotetext{
${ }^{1}$ Cambridgeshire and Peterborough Clinical Commissioning Group, Locton House, Cambridge, UK

${ }^{2}$ University of Cambridge, Cambridge, UK
}

Correspondence to Professor Martin Roland; mr108@cam.ac.uk

\section{ABSTRACT}

Objective: To determine the effect of using experienced general practitioners (GPS) to review the advice given by call handlers in NHS 111, a national service giving telephone advice to people seeking medical care.

Design: Observational study following the introduction of GPs to review call handlers' decisions which had been made using decision support software.

Setting: NHS 111 call centre covering Cambridgeshire and Peterborough.

Intervention: When a call handler using standard NHS 111 decision support software would have advised the caller to attend the hospital accident and emergency ( $A \& E$ ) department, the decision was reviewed by an experienced GP.

Main outcome measures: Percentage of calls where an outcome other than A\&E attendance was recommended by the GP.

Results: Of 1474 cases reviewed, the GP recommended $A \& E$ attendance in 400 cases $(27.1 \%)$. In the remainder of cases, the GP recommended attendance at a primary care out-of-hours centre or minor injury unit in 665 cases (45.2\%) and self-management or some alternative strategy in 409 (27.8\%).

Conclusions: Fewer callers to NHS 111 would be sent to emergency departments if the decision was reviewed by an experienced GP. Telephone triage services need to consider whether using relatively unskilled call handlers supported by computer software is the most cost-effective way to handle requests for medical care.

\section{INTRODUCTION}

The organisation of out-of-hours primary care has changed radically in England in the past 20 years. Before 1990, requests for care outside normal office hours were most often dealt with by the patient's own general practitioner (GP) or by one of the other doctors in the practice. During the 1990s, GP practices increasingly combined into rotas in
Strengths and limitations of this study

- Since 2014, telephone calls for urgent care have been handled in the English NHS by 'NHS 111' which employs call handlers using computer algorithms in order to advise patients on what they should do.

- Although the call handlers have access to some clinical advice, the service has been criticised for sending too many patients to accident and emergency (A\&E) departments.

- This small observational study suggests that fewer patients, possibly by as much as three quarters, would be sent to accident and emergency departments if the call handler's decision was reviewed by an experienced general practitioner.

- A limitation of the study is that it was a study based on experience from one out-of-hours call centre, that data were only collected over a 4-month period, and there were limited data on patient outcomes.

order to reduce the frequency of on-call duty, and many so-called 'co-operatives' started to use nurses to screen calls. In 2004, responsibility for out-of-hours care moved, and the use of nurses to screen calls became standard. In 1998 a parallel telephone service for out-of-hours advice called NHS Direct was also established, initially led by nurses but subsequently using non-clinical call handlers. NHS Direct also provided a web-based symptom checker on the NHS Direct website and for smart phones. ${ }^{1}$ The service was discontinued in 2014 being replaced by NHS 111, a triage and advice line, in February 2014.

NHS 111 employs staff who are mostly without clinical training, and the advice given is largely dependent on use of NHS Pathways software. This software allows call handlers to check symptoms and signs to arrive at an 
end point which is the disposition. Calls are initially received by the non-clinical call handlers and there are certain triggers which result in transferring the caller to a clinical advisor (usually a nurse or paramedic). The software generally requires yes or no answers to questions and is designed to deliver risk averse outcomes when used by non-clinicians. Call handlers at NHS 111 may send an ambulance to the patient, advise the caller to attend an accident and emergency (A\&E) department at the local hospital, advise the caller to visit a GP out-of-hours centre for a face-to-face consultation, or give other advice not requiring an immediate face-to-face consultation. NHS 111 was widely criticised in its early days, including concerns that the service was sending too many patients to A\&E departments, contributing to the rise in A\&E attendance. ${ }^{2}$ While such criticisms had been levelled at previous triage services, a controlled before and after study suggested that NHS 111 may also have contributed to a rise in A\&E attendance. ${ }^{3}$ Nevertheless, patients appear generally satisfied by the service offered by NHS 111. ${ }^{4}$ One of the criticisms of NHS 111 has been that judgements are made by non-clinical staff using over-rigid computer software. Clinical advisors are available to guide call operators, but the ratio of clinical advisers to call handlers is relatively small (averaging 1:4 to 1:6 in NHS 111 call centres, which may contain many call handlers).

The issue of deploying the most appropriate level of clinical advice for patients with urgent medical problems is one of international importance and debate around quality and effectiveness of care. ${ }^{5-8}$ The cost effectiveness of different approaches to staffing such services is not always clear. For example, in out-of-hours care in Denmark where GPs still take out-of-hours calls directly in some regions, a recent study concluded that the costs of out-of-hours care would rise rather than fall if nurses substituted for doctors in triaging out-of-hours calls. ${ }^{9}$ The UK is unusual in making widespread use of call handlers without previous clinical training. The call handlers receive 6 weeks training in using the computer software with ongoing monitoring and audit of calls and backup from clinical advisors who are in the main registered nurses or paramedics. In this study, we tested the use of experienced GPs to review decisions made by NHS 111 call handlers to advise patients to attend an A\&E department. The aim of the study was to determine the effect of using experienced GPs to review the advice given by call handlers in NHS 111

\section{METHOD}

In this observational study we first profiled the average rates at which patients were sent to A\&E departments following a call to the Cambridgeshire and Peterborough NHS 111 service. Baseline rates were low at around $1 / \mathrm{h}$ but increased to $5 / \mathrm{h}$ between 18.00 and 22.00 on weekdays and $6 / \mathrm{h}$ between 08.00 and 22.00 at weekends. Based on this information we placed four GPs in rotation in the call centre between 18.30 and $22.00 \mathrm{~h}$ Monday to Friday and from 08.00 to $22.00 \mathrm{~h}$ at weekends and public holidays. In our study, where the NHS Pathways software indicated that a patient should be instructed to go to an A\&E department, the call handler told the patient that they would be called back by a GP. However, for safety purposes, they were told that they should go to the A\&E department if they did not receive the call within $30 \mathrm{~min}$ or if their symptoms became worse. We only included patients who were directed to an A\&E department by the call handler, not those cases in which a clinical adviser was consulted. The GPs in our study who in many cases had access to the patient's medical record then phoned the patient and reviewed the case using his or her clinical judgement, recording the recommended disposal. We only assessed this additional step where the recommendation to go to an A\&E department had come from one of the call handlers, not when it had come from a clinical advisor in the NHS 111 service. Data were collected from September to December 2014.

\section{RESULTS}

Compared to the general population, young people and children up to age 9 years ( $18 \%$ of calls, $12 \%$ of population of Cambridgeshire) and the over 80 years (14\% of calls, $4 \%$ of population of Cambridgeshire) were overrepesented in calls to NHS 111 in Cambridgeshire and Peterborough NHS 111. Approximately $8 \%$ of calls were directed to attend an A\&E department. This compared to national figures in the year to November 2014, of $7.5 \%$ of NHS 111 calls being directed to attend an A\&E department. ${ }^{10}$ This meant that 1158349 people were directed to an A\&E department during the year, representing $6.3 \%$ of the overall number of A\&E attendances during the year (total A\&E attendance in England in the year to September 2014, excluding planned follow-up attendance was $\left.18292430^{11}\right)$. In Cambridgeshire and Peterborough, calls from NHS 111 represent approximately $16 \%$ of ambulance dispatches.

During an observational study which ran from September to December 2014 which was the time during which the service development was introduced, GPs in the Cambridgeshire and Peterborough NHS 111 service reviewed a total of 1474 cases in which the patient had been directed to an A\&E department.

Of the 1474 call handlers' cases reviewed, the GP's sent the patient to an A\&E department in 400 cases $(27.1 \%)$, to a Minor Illness and Injury Unit in 76 $(5.2 \%)$, to an out-of-hours clinic run by GPs in 589 (40\%), and would have advised self-care or some alternative management in $409(27.8 \%)$ cases. In other words, some form of management alternative to A\&E attendance would have been recommended in $73 \%$ of cases that would otherwise have been sent to the emergency department by the NHS 111 call handler.

We were not in a position formally to assess the costeffectiveness of the addition of a GP to decisions to send 
patients to A\&E departments as we did not know what action patients actually took (eg, those advised to go to an A\&E department might not have done and others advised to take alternative courses of action might still have gone to an A\&E department). However, our data suggest the potential for cost saving for A\&E departments. During the study, GPs advised a course of action other than A\&E attendance in 1072 of 1474 cases reviewed, which could have resulted in a saving of $£ 52528$ in A\&E departments (based on $£ 49$ per case http://www.pssru.ac.uk/pdf/uc/uc2011/uc2011.pdf).

This compared to the total cost of employing GPs for these sessions of $£ 41416$.

\section{DISCUSSION}

The results of this short-term observational study suggest that, if a GP had checked call handlers' decisions to send patients to the emergency department, nearly three-quarters of patients would have been advised to do something else-most commonly to attend a GP out-of-hours centre for a face-to-face consultation with a GP or a nurse. The criticisms that NHS 111 sends more patients than necessary to A\&E departments therefore appears correct, though we were not able in this study to assess the appropriateness of decisions made by either the GPs or the call handlers. Since, nationally, only $6 \%$ of A\&E attendances occur as a result of advice from NHS 111, the ability to reduce overall A\&E workload by restructuring NHS 111 is relatively small.

The study was based on data from one centre only and the findings should be replicated in other NHS 111 call centres in England. The study may have underestimated the impact of more clinical advice in NHS 111 as we looked only at decisions by the call handlers that the patient should attend an A\&E (6\% of calls) department not those cases where they decided to call an ambulance $(9 \%)$. It is possible that more senior clinical advice might have avoided a proportion of these as the introduction of NHS 111 was associated with a rise in ambulance calls. ${ }^{3}$ The study is also limited by the collection of data from only four GPs reviewing calls and by the fact that we do not have outcome data: we know only whether callers were recommended to attend an A\&E department, not whether they actually attended. Equally we do not know whether some patients diverted away from A\&E by the GP actually had serious conditions that should have been seen in hospital, and further studies in this area should include outcomes data.

The substitution of less skilled staff to take on roles traditionally provided by doctors is widespread. For example, nurses are now widely used in UK general practice both to see patients with acute illness and to provide chronic disease management. However, such changes, while being effective, may not always be cost-effective. A systematic review of nurse-doctor substitution in general practice concluded that nurses can provide safe and effective care but that the cost savings achieved by the lower salaries of nurses were offset by lower productivity. ${ }^{12}$ For example, in one randomised controlled trial of nurse practitioners in general practice, cost savings by employing nurses were offset by the nurse having longer consultations, carrying out more tests and asking patients to return more frequently. ${ }^{13}$

In this study we examined the effect of having the decisions of call handlers reviewed by GPs, a relatively expensive resource. A number of alternatives could have been tested and do form part of telephone triage services in other settings and countries, most commonly the use of registered nurses as call handlers. There is also variation in the support systems which call handlers use, for example whether they are mandated to use a software system that is inevitably risk-averse or whether they can use their clinical judgement.

It seems ironical that at a time when out-of-hours primary care services have progressively moved to less skilled people handling calls (from doctors to nurses to call handlers), hospitals have done the reverse. In hospitals, decisions to admit patients were traditionally made by junior hospital doctors. Now NHS hospitals increasingly have senior (consultant) doctors available to make decisions about admission. This is because of the pressure to reduce admissions and the belief that senior doctors are better equipped to make safe decisions that the patient does not need admitting. By relying on staff without clinical training to make decisions based on a computer algorithm, NHS 111 will inevitably request a higher level of care than may be necessary in order to operate safely. The study suggests that there could be substantial benefits, and possible cost reductions, by engaging experienced GPs in out-of-hours triage decisions within NHS 111. We are not suggesting from the results of this study that GPs should take all out-of-hours calls, or even that they should necessarily screen all recommendations for $\mathrm{A} \& \mathrm{E}$ attendance made by the call handlers. However, we do think that our results demonstrate the need for further research to establish the costeffectiveness of different approaches to triaging telephone requests for care.

\section{Twitter Follow Martin Roland at @ProfRoland}

Contributors AA organised the intervention evaluated in this study and is the guarantor. MR assisted in analysis of the data and wrote the first draft of the paper.

Competing interests AA leads for commissioning NHS 111 services in Cambridgeshire and Peterborough Clinical Commissioning Group.

Funding Cambridgeshire and Peterborough CCG funded the general practitioner time to review call handler decisions as part of their service development.

Provenance and peer review Not commissioned; externally peer reviewed.

Data sharing statement Additional data are available from AA (andrew. anderson@nhs.net). 
Open Access This is an Open Access article distributed in accordance with the Creative Commons Attribution Non Commercial (CC BY-NC 4.0) license, which permits others to distribute, remix, adapt, build upon this work noncommercially, and license their derivative works on different terms, provided the original work is properly cited and the use is non-commercial. See: http:// creativecommons.org/licenses/by-nc/4.0/

\section{REFERENCES}

1. NHS Direct. http://en.wikipedia.org/wiki/NHS Direct

2. lacobucci G. GPs back call for independent review of "dreadful" NHS 111. BMJ 2013;346:f3437.

3. Turner J, O'Cathain A, Knowles E, et al. Impact of the urgent care telephone service NHS 111 pilot sites: a controlled before and after study. BMJ Open 2013;3:e003451.

4. O'Cathain A, Knowles E, Turner J, et al. Acceptability of NHS 111 the telephone service for urgent $\mathrm{l}$ : cross sectional postal survey of users' views. Fam Pract 2014;31:193-200.

5. Staub GM, von Overbeck J, Blozik E. Teleconsultation in children with abdominal pain: a comparison of physician triage recommendations and an established paediatric telephone triage protocol. BMC Med Inform Decis Mak 2013;13:110.
6. Sakurai $\mathrm{A}$, Morimura $\mathrm{N}$, Takeda $\mathrm{M}$, et al. A retrospective quality assessment of the 7119 call triage system in Tokyo-telephone triage for non-ambulance cases. J Telemed Telecare 2014;20:233-8.

7. Wheeler SQ, Greenberg ME, Mahlmeister L, et al. Safety of clinical and non-clinical decision makers in telephone triage: a narrative review. J Telemed Telecare 2015;21:305-22.

8. Pasini A, Rigon G, Vaona A. A cross-sectional study of the quality of telephone triage in a primary care out-of-hours service. $J$ Telemed Telecare 2015;21:68-72.

9. Moth G, Huibers L, Vedsted P. From doctor to nurse triage in the Danish out-of-hours primary care service: simulated effects on costs. Int J Family Med 2013;2013:987834.

10. NHS England. NHS 111 Minimum dataset. http://www.england.nhs. uk/statistics/category/statistics/nhs-111-statistics/

11. Health and Social Care Information Centre. Provisional Accident and Emergency Quality Indicators-England, by provider. http://www. hscic.gov.uk/article/2021/Website-Search?q=A\% 26E\&go=Go\&area $=$ both

12. Laurant M, Reeves D, Hermens R, et al. Substitution of doctors by nurses in primary care. Cochrane Database Syst Rev 2005;(2): CD001271.

13. Venning $\mathrm{P}$, Durie $\mathrm{A}$, Roland $\mathrm{M}$, et al. Randomised controlled trial comparing cost effectiveness of general practitioners and nurse practitioners in primary care. BMJ 2000;320:1048-53. 